\title{
Latency of the blink reflex and stimulus intensity '
}

EOWARD O. BIXLER, NEIL R. BARTLETT AND ROBERT W. LANSING

\author{
DEPARTMENT OF PSYCHOLOGY, UNIVERSITY OF ARIZONA
}

The latency of the eyeblink reflex is inversely related to the intensity of the auditory or visual stimuli used to evoke it. This is true for both mechanical and muscle action potential me thods for recording the response.

Investigators using the eyeblink as the response have validated their results by a comparison with published data on the reflex blink (Dodge, 1913; Hilgard, 1931). These data have included little or no specification of the stimulus parameters; a single figure for the reflex time typically is cited. However, behavioral data using the visual sense modality show that latency is a function of intensity. For example, the relationship between simple manual reaction and stimulus intensity (Cattell \& Dolley, 1895; Froeberg, 1907; Wells, 1913; Bartlett \& Macleod, 1954), a varied background intensity with a constant stimulus intensity (Steinman, 1944; Steinman \& Veniar, 1944; Bartlett \& Macleod, 1954), and varied degrees of dark adaptation (Lemmon \& Geisinger, 1936; Macleod \& Bartlett, 1954) have all demonstrated that a simple motor response to light depends upon stimulus intensity and the state of the receptor. But the relationship between the latency of the reflex eyeblink and the stimulus intensity apparently has not yet been demonstrated. This report is intended to meet that need, and to compare two methods of blink recording.

\section{Method}

Eyeblink latencies to visual and auditory stimuli of varying intensities were obtained using both mechanical and electromyographic recording techniques. The visual stimuli were single flashes of $10 \mu \mathrm{sec}$ duration, delivered by a Grass PS 2 photostimulator. Stimuli were presented at the five standard intensity levels of the instrument: $12,500,50,000,200,000,600,000$, and 1,000,000 peak $\mathrm{cp}$. The flashes were diffused and polarized at the lamp face, with an intensity loss of about $6.9 \mathrm{ft}-\mathrm{c}$, and the $\mathrm{S}$ viewed the lamp from a distance of $25 \mathrm{~cm}$. The sound stimuli were single clicks presented to the $S$ through headphones. Square electrical pulses of $1.2 \mathrm{~V}$ and $0.1 \mathrm{msec}$ in duration were produced by a Grass $\$ 4$ stimulator and attenuated by a Grass AM-3 audio amplifier to deliver clicks at intensities of $80,90,100,105$, and $110 \mathrm{~dB}$. These intensities were calibrated with an Allison Lab 300 calibration unit.

Two methods were used to record latency. The first, recording the mechanical movement of the eyelid, employed an optical system with a selenium photocell and flexible fiber attached to an aluminum bracket shaped to the S's head. This whole assembly was mounted on the head with an elastic band so that the shadow from the moving eyelash altered the output of the photocell. The second method was a direct recording of the muscle action potentials of the orbicularis oculi M. of the upper lid. Two small electrodes $(2 \mathrm{~mm}$ diameter) were applied to the upper lid so as not to impair the latency of the eyelid response and to provide a recording free from ERG, eye movement, or mechanical artifacts. Potentials from the eyelid muscles were amplified with a Grass P5 preamplifier and recorded by a Honeywell 906 Visicorder at a paper speed of $25 \mathrm{in} . / \mathrm{sec}$. The latency to the first deflection from the baseline after a stimulus was measured to the nearest msec.

The photocell employed in the eyelid response also indicated the onset of the stimulus. The stimulus light was polarized $90^{\circ}$ out of phase with the photocell in order to prevent the overdriving of the photocellpreamplifier system by the high intensity flash. The occurrence of the click stimulus was signaled by the electrical artifact produced on the record during its delivery.

Three college students with no apparent visual or auditory defects served as Ss. They were dark adapted for about $10 \mathrm{~min}$, then instructed to look at a small spot of luminous paint at the center of the light stimulus whenever their eyes were open. Stimuli were presented only when the photocell potential on an oscilloscope monitor indicated that the eyelash was in the desired position.

Five records at each intensity were collected for both flashes and clicks for each of five days. The stimuli were presented in a Graeco-Latin square design to counterbalance sequential effects of different intensities and to permit examination of the effects of habituation or adaptation for any given intensity during the session. Stimuli were presented approximately once every $\mathrm{min}$, with flash and click in alternation. The paper drive for the Visicorder was activated $.25 \mathrm{sec}$ prior to stimulus presentation. Because occasionally stimuli were presented in the refractory period of an immediately preceding eyeblink, records which showed any activity during this prestimulus period were eliminated from consideration.

\section{Results}

The results presented in Fig. 1, based on data for all Ss, show that the reflex eyeblink latency is inversely related to stimulus intensity for both auditory and visual stimuli within the limits tested. In an analysis of variance, Treatment by Ss design, 

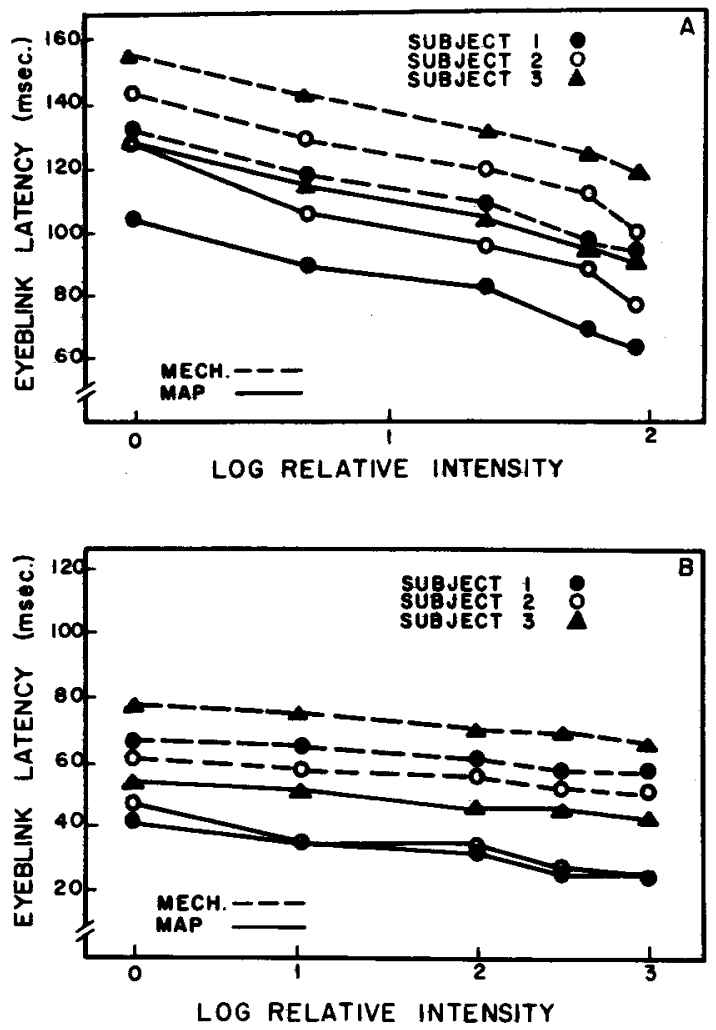

Fig. 1. Mean eyeblink latency plotted as a function of the intensity of visual stimuli $(A)$ and auditory stimuli (B). Solid line, muscle action potential measures (MAP); dashed line, mechanical measures (MECH).

the effect of intensity on reflex latency was significant $(p<.01)$, while stimulus repetition, time in the dark, and stimulus order were shown to have no significant effect. The response times to auditory stimuli were consistently shorter than those to light stimuli, and the slopes of the auditory and visual intensity curves were markedly different. These differences presumably are due to the fact that the intensity ranges and intervals covered in the two modalities were not equated on any psychophysical scale; perhaps the auditory intensities were relatively much greater producing shorter latencies and a more flat slope.

Comparison of the mechanical and action potential records shows the two to be equally affected by stimulus change; the interval between the onset of the muscle potential response and the first mechanical deflection was remarkably constant for a given $S$. The muscle potential method was the more stable of the two (tested by the Kruskal-Wallis analysis of variance), but since the instrumentation is quite different the slight increase in stability is bought at some cost.

It should be remembered that latency is only one aspect of reflex response, and the relationships observed in this study may not necessarily hold when another response measure, such as amplitude, is employed.

\section{References}

Bartlett, N. R., \& Macleod, S. Effect of flash luminance upon human reaction time. J. Opt. Soc. Amer., 1954, 44, 306-311.

Cattell, J. M., \& Dolley, C. S. On reaction times and the velocity of the nervous impulse. Nat. Acad. of Sci., Mem., 1895, 7, 393-415.

Dodge, $\mathbf{R}$. The refractory phase of the protective wink reflex. Amer. J. Psychol., 1913, 24, 1-7.

Froeberg, S. The relation between the magnitude of stimulation and the time of reaction. Arch. Psychol., 1907, 1, No. 8.

Hilgard, E. R. Conditioned eyelid reactions to a light stimulus based on the reflex wink to sound. Psychol. Monogr., 1931, 41, No. 184.

Lemmon, V. W., \& Geisinger, S. M. Reaction time to retinal stimulation under light and dark adaptations. Amer. J. Psychol., 1936, 48, $140-142$.

Macleod, S., \& Bartlett, N. R. Human reaction time during dark adaptation. J. Opt. Soc. Amer., 1954, 44, 374-379.

Steinman, A. Reaction time to change. Arch. Psychol., 1944, 41, No. 292 .

Steinman, A., \& Veniar, S. Simple reaction time to change as a substitute for dysjunctive reaction time. J. exp. Psychol., 1944, 34, 152-158.

Wells, G. R. Influence of stimulus duration on reaction time. Psychol. Monogr., 1913, 15, No. 5.

\section{Nole}

1. This work was supported by grant GB3955 of the National Science Foundation to the University of Arizona.

(Accepted for publication June 27, 1967.) 